\title{
RITUAL DE SALVACIÓN \\ CENTRADO EN LA CRÓNICA \\ DE LA JORNADA DE OMAGUA Y DORADO
}

Salvation ritual centred on the Chronicle OF THE JOURNEY OF OMAGUA AND DORADO

\section{ALEJAN DRA LEAL LADRÓN DE GUEVARA ${ }^{1}$}

\section{RESUMEN}

Este estudio comparativo describe el carácter sagrado del ritual de la salvación presente en un corpus compuesto por los discursos de la Crónica de la Jornada de Omagua y Dorado de Francisco Vásquez y Pedrarías de Almesto (1561), con tres novelas del siglo $\mathrm{XX}$ y cuatro lecturas de textos precolombinos. En este contexto, aplicaremos el modelo genético del mito representado en las haces de las relaciones en las unidades sintagmáticas de los componentes del ritual (Lévi-Strauss, 1976) de la lengua natural y la significación subyacente, sólo aprehensible en el contexto de un modelo ejemplar presente en una de las actividades humanas más significativas: el ceremonial de la expiación de la culpa y mediatizado por el ritual de la salvación.

Palabras clave: Mito, ritual, trama.

\section{ABSTRACT}

This comparative study describes the sacred character of the salvation ritual that appears in a corpus conformed by the discourses of TheChronicle of the J ourney of O magua and Dorado by Francisco Vásquez and Pedrarías de Almesto (1561), with three novels from the XXth Century and four readings of pre-Columbian texts. In this context, we will apply the genetic model of the myth represented in the bundles of relations in the syntagmatic units of the ritual components (Lévi-Strauss, 1976) of natural language and its underlying meaning, only comprehensible in the context of an exemplary model

${ }^{1}$ Doctora en Ciencias Humanas, Lingüística y Literatura, Área de Comunicación y Lenguaje Español, Universidad Austral de Chile Sede Puerto Montt, Puerto Montt, Chile. E-mail: alejandraleal@uach.cl 
present in one of the most important human activities: the ceremony of expiation of guilt mediated through the salvation ritual.

Keywords: Myth, ritual, plot.

Recibido: 06.09.2007. A probado: 12.09.2008.

\section{INTRODUCCIÓN}

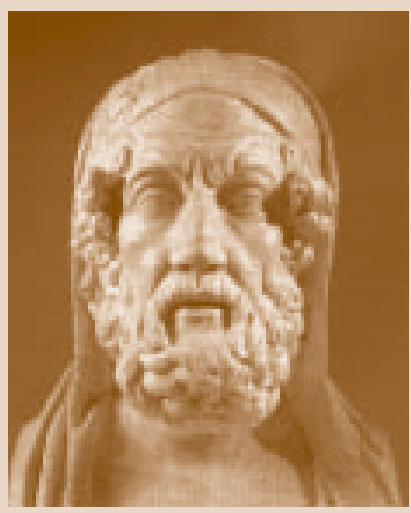

Homero

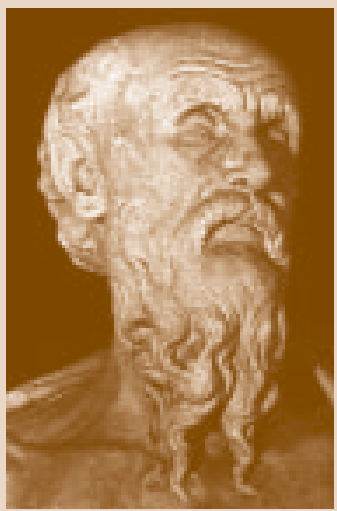

Hesíodo

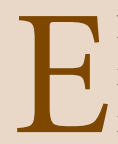

N LA historia del hombre, las grandes culturas han contado con una mitología. Éstas han sido relatadas, modificadas, articuladas y sistematizadas por el hombre desde los tiempos míticos. Hesíodo, autor de La teogonía (s. VII a. de C.), enuncia una rica recopilación de la erudición religiosa que describe y comenta hechos de los orígenes, o como lo expresa también el mismo Homero, a quien se le atribuye la autoría de las dos famosas obras épicas La llíada y La odisea, desde donde conocemos las historias y hazañas de grandes personajes de la mitología de la antigüedad griega (Bowra, 1996). Mircea Eliade (1999: 13) reseña entre las definiciones del mito aquella que cuenta una historia sagrada, agregando que dentro de las funciones, la más importante es la de "revelar los modelos ejemplares de todos los ritos y actividades humanas significativas", ya que no sólo importa lo que implica la historia sagrada de los pueblos, sino aquello que presupone. Es decir, considerar lo verdadero, puesto que "en las historias 'verdaderas' nos encontramos frente a frente con lo sagrado o lo sobrenatural; en las 'falsas', por el contrario, con un contenido profano" (Eliade, 1999: 15, 16).

Lo que aconteció al hombre en las sociedades arcaicas es susceptible de repetirse por la fuerza de los ritos. A través de éstos, rememorándolos y reactualizándolos, el hombre repite lo que los dioses, los héroes o los antepasados hicieron. Es a través de la experiencia de lo sagrado que se abren paso las ideas de la realidad, la verdad y la significación, asimismo, el ritual permite abolir el tiempo profano, cronológico, y recuperar el tiempo sagrado del mito. El hombre, donde el mito es algo latente, vive en un mundo "abierto", aunque "cifrado" y misterioso, pues la manera de comprender este lenguaje es por el conocimiento del carácter de los mitos y descifrando los símbolos (Eliade, 1999: 137). No obstante, para dar cuenta de estos caracteres del pensamiento mítico, en distintas regiones del mundo debemos escudriñar más allá del lenguaje, ya que las propiedades del mito subyacen a las expresiones de éste. La consecuencia del mito está presente en las unidades constitutivas de la entidad lingüística, cuyo sentido subyacente se abstrae del sentido gradual de estas unidades superficiales reducidas a las relaciones 
conformadas por los términos sintagmáticos y de las funciones formuladas por éstas; complementariamente, la repetición del patrón de la estructura sincrónica ordenada en secuencias diacrónicas caracterizará al mito, cuyo objetivo será el de proporcionar un modelo lógico para resolver las contradicciones o limitaciones que presenta el mismo lenguaje (Lévi-Strauss, 1976: 191, 209).

En este estudio descriptivo-comparativo analizaremos el carácter sagrado del ritual de la salvación presente en un corpus textual que toma como referente el discurso de la Crónica de la Jornada de Omagua y Dorado de Francisco Vásquez y Pedrarías de Almesto (1561), asimismo, en relación con aquellos discursos referenciales del ritual en las novelas El camino deEI Dorado de Arturo Uslar Pietri (1967), LopedeAguirre, príncipedela libertad de Miguel Otero Silva (1980) y La aventura equinoccial de Lope deAguirre de Ramón Sender (1980), como también los discursos seleccionados entre los naturales. En este contexto, describiremos un primer sentido anecdótico del ceremonial representado en las haces de las relaciones de las unidades sintagmáticas y de los componentes del ritual (Lévi-Strauss, 1976) en una trama compuesta por la tríada de personajes: Antón Llamoso, Lope de Aguirre y Martín Pérez también presentes en el corpus de novelas como lo referido entre los naturales. Así, pasaremos del hecho manifestado por la lengua entre los naturales americanos para llegar a aquél de la significación subyacente, sólo aprehensible en el contexto de un modelo ejemplar presente en una de las actividades humanas más significativas: el hijo que busca el perdón del padre mediatizado por el ritual de la salvación de la muerte individual o colectiva, de la pérdida del poder o del caos.

\section{MARCO REFERENCIAL}

Iniciamos nuestro estudio con la definición de mito y ritual reseñada por Mircea Eliade (1999: 13), quien expresa que mito es aquel que cuenta una historia sagrada, cuya función más importante es la de "revelar los modelos ejemplares de todos los ritos y actividades humanas significativas", ya que no sólo importa lo que implica la historia sagrada de los pueblos, sino aquello que presupone. Por su parte, Manuel Gutiérrez (1988:2) sostiene que los ritos, en uno de los casos, son acciones dirigidas a buscar la protección simbólica, en suma, recrear las creencias subyacentes dando sentido a la vida personal y a la realidad social. En suma, a través de los rituales consideramos lo verdadero, puesto que "en las historias 'verdaderas' nos encontramos frente a frente con lo sagrado o lo sobrenatural; en las 'falsas', por el contrario, con un contenido profano" (Eliade, 1999: 15,16). De manera que el mito 
dará cuenta de una historia sagrada, siendo el rito la función que está al servicio de éste. Así mismo, con el mismo propósito de analizar un hecho de la historia de esta Crónica tomaremos las definición de trama dada por Tomachevsky (en Hozven, 1979), entendida como "el conjunto de acontecimientos considerados en sucesión cronológica y en sus relaciones de causa a efecto", pues a partir de esto reconoceremos al interior de las secuencias las transformaciones que den cuenta de la historia consciente, y el contenido inconsciente que el mito busca resolver, ya que "sea lo que fuere el inconsciente, es un fenómeno natural que produce símbolos que tienen significado" (Jung, 1995: 102). De esta manera, sostenemos que la verdadera y significativa función de la experiencia humana en esta tríada de conquistadores concebida en la secuencia de esta trama fue la de contribuir a recrear y dar sentido al ritual del perdón con la consecuente salvación.

En este contexto discursivo nos serviremos de la fórmula genética presentada por Lévi-Strauss (1976) para revelar el primer sentido anecdótico del ceremonial representado en las haces de las relaciones de las unidades constitutivas de la historia; reparando en que las unidades constitutivas del mito no son las relaciones aisladas, sino "haces de relaciones", es decir, la relación de estas unidades cuyo propósito está en alcanzar una función significante. A partir de la fórmula [Fx (a): $\mathrm{Fy}(\mathrm{b})=\mathrm{Fx}(\mathrm{b})$ : $\mathrm{Fa}-\mathrm{l}(\mathrm{y})]$, primero, revisaremos los sintagmas formados por frases cortas y significativas de la secuencia de la trama, obteniendo con ello el contenido ordenado cronológicamente; luego observaremos la lectura del esquema paradigmático, es decir, de la continuidad de las dos columnas del esquema binario que nos permite reconocer el contenido subyacente el que, finalmente, nos revelará la matriz que restituye la ley estructural del mito. Por su parte, Strauss representó estas ideas como un sistema de dimensiones sincrónica y diacrónica para reunir las propiedades características de la lengua y el habla. No obstante, nosotros emplearemos esta relación adaptada a nuestro corpus discursivo tomando como referente el texto de Vásquez y Pedrarías de Almesto, haciendo referencia a discursos precedentes de las culturas precolombinas.

En este sentido, contamos con referencias de los rituales de sacrificio en "las tallas de las esteras mayas en que se ve a las víctimas extendidas sobre piedras sacrificiales mientras el sacerdote levanta el brazo armado de un cuchillo" (Clissold, 1965: 22); como de manera semejante en el libro del Popol Vuh, de las tradiciones de los indios quichés, en su Tercera parte se habla del origen de los pueblos indígenas de Guatemala, sus emigraciones, su distribución en el territorio, sus guerras y el predominio de la raza quiché hasta poco antes de la conquista española, y es en el Capítulo II y Cuarta parte en donde se hace mención de los rituales guerreros señalando: "He 
aquí como comenzó el robo de los hombres de las tribus [de Vuc Amag] por Balam-Quitzé, Balam-Acab, Mahucutah e Iqui-Balam... Luego vino la matanza de las tribus... y no se sabía cuándo los cogían, y enseguida los iban a sacrificar ante Tohil y Avilix" (Recinos, 1952: 128). "Y ésta era la abertura que había dicho Tohil: que sacrifican a todas las tribus ante él, que se les arrancara el corazón del pecho y del sobaco" (Recinos, 1952: 115); otra forma ejemplar la encontramos entre los naturales Arnaquinas, por donde pasan los de Aguirre, quienes creen ver allí las "casas de adoratorio para sus ritos y sacrificios" como a "la puerta de cada casa destos hay dos sacrificaderos, adonde nos pareció que deben de degollar los indios que sacrifican" (Vásquez y De Almesto, [1561] 1986: 65); además, el texto de Viajes y cautiverio entre los caníbales, de Hans Standen, correspondiente a parte de la tesis de maestría de la doctora Clicie Nunes, quien dirá que el verdadero "motivo del ritual es fortalecer al guerrero a través de los complejos procesos mágicos de adquisición de poder, por la ingestión de la carne del enemigo" (Nunes, 1988). Un fragmento del discurso de Standen expone que: las antiguas tribus tupís practican el ritual de la captura de hombres entre los Tupinambáes y Tupiniquins, combatiendo con el objeto de capturar prisioneros vivos para el sacrificio e ingesta, siendo la ceremonia preparada con mucha antelación e implicando organización y trabajo según normas rituales establecidas. Así mismo, en la Teogonía e historia de los mexicanos, según la traducción de Ángel Garibay (1973), reconocemos la función: alimentar, conquistar y subyugar para lograr la piedad del dios, como acontece en el M ito dela creación en la teogonía de mexicanos (1973: 108) en donde la función es recrear el espacio de la naturaleza que da los frutos a través del sacrificio de los corazones humanos. Además, al interior de las comunidades araucanas existen reveladoras historias en las que se justifica este hecho expiatorio y de salvación como en la Leyenda de Licarayén (versión de Antonio Landauro, 1982), en donde se extrae el corazón de una muchacha para aplacar la ira de un ser sobrenatural que habita en el centro del volcán Osorno, el Pillán junto a sus machis, quienes odiaban el trabajo asolando a las tribus cercanas al lago Llanquihue; se comenta que para vencerlo se debía arrojar al cráter del volcán una hoja de canelo, ya que luego caería la nieve, taparía el cráter y el genio quedaría atrapado. Sin lograrlo aún, un anciano profetiza diciendo: "para llegar al cráter es necesario que sacrifiquéis a la virgen más hermosa de la tribu. Debéis arrancarle el corazón y colocarlo en la punta del pichi Juan, tapado con una rama de canelo. Veréis, entonces, que vendrá un pájaro del cielo, se comerá el corazón y después llevará y dejará caer la rama de canelo en el cráter del volcán". 
Este episodio desarrollado ante Aguirre recrea un ritual que, por un lado, es natural a las comunidades cercanas. Recordemos que Aguirre y sus hombres pasaron por una comunidad que adoptaba estos rituales con un valor sagrado. Es una descripción de la ruta de los Omaguas por donde Aguirre y sus marañones se desplazan, luego de dos días de haber dado muerte a Fernando de Guzmán, pues yendo río abajo desde isla Margarita, a siete días divisan la cordillera, cabañas y sierras peladas; aquí, los guías dicen encontrarse entre los Omaguas debido a la buena tierra que los circunda. En aquella ocasión, Aguirre manda silenciar esto último tomando un desvío, entre otra cordillera de cabañas y tierras vacías, luego a la derecha observan el río desde una barranca muy alta, donde los cronistas describen lo siguiente: "Son estos indios desnudos y flecheros; son caribes; llámanse los Arnaquinas, son bien dispuestos: tienen yerba muy mala, y casas de adoratorio para sus ritos

y sacrificios; y a la puerta de cada casa destos hay dos sacrificaderos, adonde nos pareció que deben de degollar los indios que sacrifican" (1561: 65).

\subsection{Fórmula canónica}

La aplicación de la fórmula canónica propuesta para el ritual de la salvación en los hechos ocurridos en la historia contada en el texto Crónica de la jornada de O magua y D orado (1561) como en los otros, se evidencian tramas precedentes que llamaremos trama 0 .

En la línea sintagmática de la trama 1 leemos los términos en dos secuencias binarias, la primera, iniciada con la acusación / negación; en la segunda, con la anunciación / prueba, dando término al proceso del ceremonial en el triángulo vital entre Antón Llamoso, Lope de Aguirre y Martín Pérez y, en cuya primera lectura natural se revela el contenido ordenado cronológicamente de la siguiente manera:

I. La jornada de Omagua y Dorado de Francisco Vásquez y Pedrarías de Almesto (1561).

Trama 0. Muerte sangrienta de Martín Pérez: el cuerpo inmolado.

Trama 1 y secuencia del estudio:

1. Antón Llamoso acusado de traición por Aguirre: "Y voz, hijo, Antón Llamoso, también dicen que queríades matar a vuestro padre. 
2. Negación, reniegos y juramentos por las acusaciones dichas por Cristóbal García delante de Aguirre.

3. Antón Llamoso promete verbalmente beber la sangre del traidor: ““a este traidor beberle he la sangre"; que causó grande admiración a todos".

4. Antón Llamoso da prueba actitudinal succionando la sangre y sesos de Martín Pérez.

Asimismo, los demás textos conservan la misma secuencia, partiendo por la trama 0 y las secuencias binarias en la línea sintagmática que a continuación reproducimos:

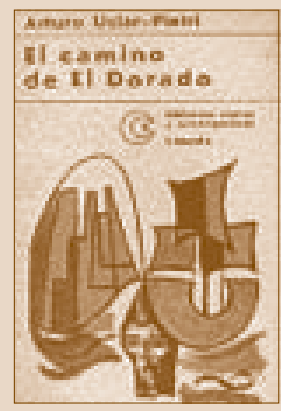

II. El camino de El Dorado de Arturo Uslar-Pietri (1967).

Trama 0. Muerte sangrienta de Martín Pérez.

Trama 1 y secuencia en el texto:

1. Aguirre acusa a Antón Llamoso: "Y vos, hijo, Antón Llamoso, dicen que también queríais matar a vuestro padre".

2. Antón Llamoso niega la acusación hecha por Cristóbal García al oído de Aguirre: "No, no, no es cierto".

3. Antón Llamoso verbaliza sus intenciones: “¡A este traidor he de beberle la sangre!"

4. Acción: Llamoso lame la sangre y masca los sesos.

III. Lope de Aguirre, príncipe de la libertad. Miguel Otero Silva (1980).

Trama 0. Muerte sangrienta de Martín Pérez.

Trama 1:

1. Aguirre acusa a Antón Llamoso: "Y vos, Antón Llamoso, queréis matar a vuestro hermano, queréis menoscabar la honra de vuestro padre".

2. Antón Llamoso jura por los huesos de sus antepasados que jamás ha desconocido la autoridad de Aguirre.

3. Antón Llamoso verbaliza sus intenciones: "he de beberle la sangre, he de mascarle los sesos".

4. Antón Llamoso sorbe con sus labios la sangre y los sesos del enemigo. 
IV. La aventura equinoccial de Lope deAguirre. Ramón Sender (1980).

Trama 0. Martín Pérez es muerto, le disparan, dan lanzadas y degüellan.

Trama 1 y secuencia de este estudio:

1. Aguirre acusa a Antón Llamoso de traidor: "Cómo es que formáis ligas con el mando de la armada".

2. Antón asegura lealtad a Lope de Aguirre.

3. Antón Llamoso promete comer los sesos y el corazón del cobarde.

4. Llamoso da prueba actitudinal ensanchando con su daga la herida abierta en el pecho de Pérez.

Textos referenciales entre los naturales:

V. Popol Vuh. Antiguas historias del quiché. Traducción de Adrián Recinos (1952).

0 . Guerras tribales.

1. Balam roba o rapta hombres de la tribu de Vuc Amag y riega la sangre en el camino.

2. Negación del hecho, justifican diciendo: "El tigre se los comió".

3. Balam ofrece el sacrificio al dios Tohil.

4. Arrancar el corazón ante Tohil (dios).

VI. Viajes y cautiverio entre caníbales. Hans Standen (1554).

0. Guerra entre Tupinambáes y Tupiniquins.

1. Combate por la captura de prisioneros vivos o dar muerte en combate.

2. Alimentación del prisionero destinado a la antropofagia.

3. El guerrero golpea o masacra el cráneo del enemigo.

4. Beneficio del alimento.

VII. Teogonía ehistoria delosmexicanos. Traducción de Angel Garibay (1973).

0. Guerras tribales entre los aztecas para sacrificar víctimas a Quetzacoatl y Huitzilopochtli.
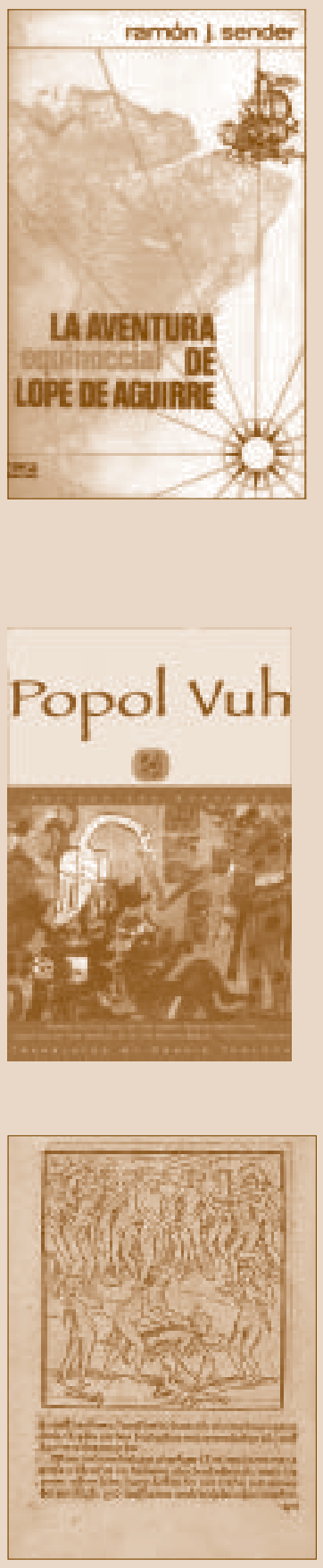
$43 \stackrel{\text { Atenea } 501}{\mid \text { | Sem. } 2010}$ 


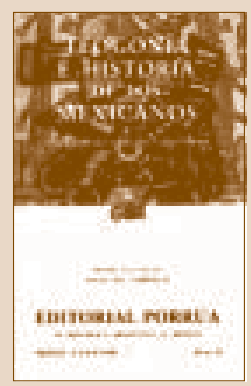

1. los aztecas capturan prisioneros.

2. los aztecas ponen al prisionero en la piedra de sacrificio

3. el sacerdote arranca desde el pecho el corazón palpitante.

4. Sacerdote ofrece el corazón a Quetzacoatl y Huitzilopochtli.

VIII. M ito dela creación en la Teogonía de mexicanos. Ángel Garibay (1973: 108)

0. Los dioses Quetzalcoatl y Tezcatlipuca desean hacer la tierra.

1. Hombres convertidos en sierpes aprietan a la diosa Tlaltecutli y la parten en dos: cielo y tierra.

2. Diosas consuelan y ordenan a Tlaltecutli (compensan a la diosa por el daño).

3. Las diosas hacen brotar la naturaleza de la diosa Tlaltecutli.

4. La diosa Tlaltecutli calma su llanto comiendo corazones de hombres.

IX. Leyenda de Licarayén (versión de Landauro, 1982)

0. Los indígenas buscan el corazón de la virgen más hermosa para aplacar la ira del Pillán.

1. El cacique entrega a su hija Licarayén.

2. La joven Licarayén acepta el sacrificio.

3. El toqui Quiltrapique extrae el corazón de Licarayén.

4. Un cóndor come el corazón y la hoja es transportada a la cima del volcán.

Mediante el ordenamiento de la lectura de este episodio hemos dado cuenta de las relaciones que se producen en el sintagma fraseológico, dando origen a la secuencia del contenido de la trama. A continuación, revisaremos la relación estructural del sintagma y de la paradigmática de los textos para descubrir el sentido profundo de la funcionalidad de este mito de salvación.

\subsection{Estructura del esquema binario}

La doble distribución binaria de esta trama nos permite estructurar el siguiente esquema: 


\begin{tabular}{|c|c|c|c|c|}
\hline $\begin{array}{l}\text { Sintagma } \\
\text { Paradigma }\end{array}$ & 1. Acusación. & 2. Negación & 3. Anunciación & 4. Prueba \\
\hline $\begin{array}{l}\text { I. La Jornada de } \\
\text { Omagua y Dorado. }\end{array}$ & $\begin{array}{l}\text { Aguirre acusa de } \\
\text { traición a Antón } \\
\text { Llamoso }\end{array}$ & $\begin{array}{l}\text { Llamoso } \\
\text { niega las } \\
\text { acusaciones } \\
\text { de Aguirre. }\end{array}$ & $\begin{array}{l}\text { Llamoso promete } \\
\text { verbalmente acabar } \\
\text { con el traidor } \\
\text { Martín Pérez. }\end{array}$ & $\begin{array}{l}\text { Llamoso enfrente } \\
\text { de Aguirre } \\
\text { succiona la sangre y } \\
\text { sesos del enemigo. }\end{array}$ \\
\hline $\begin{array}{l}\text { II. El camino de } \\
\text { El Dorado. }\end{array}$ & $\begin{array}{l}\text { Aguirre acusa de } \\
\text { traición a Antón } \\
\text { Llamoso }\end{array}$ & $\begin{array}{l}\text { Llamoso } \\
\text { niega la } \\
\text { Acusación. }\end{array}$ & $\begin{array}{l}\text { Llamoso expresa } \\
\text { verbalmente beber } \\
\text { la sangre del trai- } \\
\text { dor. }\end{array}$ & $\begin{array}{l}\text { Llamoso enfrente } \\
\text { de Aguirre lame la } \\
\text { sangre y masca los } \\
\text { sesos del enemigo. }\end{array}$ \\
\hline $\begin{array}{l}\text { III. Lope de Aguirre, } \\
\text { príncipe de } \\
\text { la libertad. }\end{array}$ & $\begin{array}{l}\text { Aguirre acusa de } \\
\text { traidor de la honra } \\
\text { a Antón Llamoso. }\end{array}$ & $\begin{array}{l}\text { Llamoso niega } \\
\text { por sus ante- } \\
\text { pasados al frente } \\
\text { de Aguirre. }\end{array}$ & $\begin{array}{l}\text { Llamoso promete } \\
\text { beber la sangre y } \\
\text { mascar los } \\
\text { sesos de Pérez. }\end{array}$ & $\begin{array}{l}\text { Llamoso enfrente } \\
\text { de Aguirre succiona } \\
\text { con sus labios la } \\
\text { sangre y los sesos } \\
\text { del enemigo. }\end{array}$ \\
\hline $\begin{array}{l}\text { IV. La aventura } \\
\text { equinoccial de } \\
\text { Lope deAguirre }\end{array}$ & $\begin{array}{l}\text { Aguirre acusa de } \\
\text { confabulador } \\
\text { a Antón Llamoso. }\end{array}$ & $\begin{array}{l}\text { Llamoso asegura } \\
\text { lealtad a Aguirre. }\end{array}$ & $\begin{array}{l}\text { Llamoso promete } \\
\text { comer los sesos y } \\
\text { el corazón del } \\
\text { cobarde. }\end{array}$ & $\begin{array}{l}\text { Llamoso delante de } \\
\text { Aguirre ensancha } \\
\text { con su daga la herida } \\
\text { en el pecho de Pérez. }\end{array}$ \\
\hline 01. Popol Vuh. & $\begin{array}{l}\text { Balam roba o rapta } \\
\text { hombres de la tribu } \\
\text { de Vuc Amag y riega } \\
\text { la sangre en el camino. }\end{array}$ & $\begin{array}{l}\text { Negación del } \\
\text { hecho, diciendo } \\
\text { "El tigre se } \\
\text { los comió". }\end{array}$ & $\begin{array}{l}\text { Balam ofrece } \\
\text { el sacrificio } \\
\text { al dios Tohil }\end{array}$ & $\begin{array}{l}\text { Balam arranca el } \\
\text { corazón delante de } \\
\text { Tohil (dios). }\end{array}$ \\
\hline $\begin{array}{l}\text { 02. Viajes y cautiverio } \\
\text { entre caníbales. } \\
\text { Hans Standen. }\end{array}$ & $\begin{array}{l}\text { Combate por la } \\
\text { captura de prisioneros } \\
\text { vivos o dar muerte } \\
\text { en combate. }\end{array}$ & $\begin{array}{l}\text { Alimentación del } \\
\text { prisionero } \\
\text { destinado a } \\
\text { la ingesta }\end{array}$ & $\begin{array}{l}\text { El guerrero golpea } \\
\text { o masacra el cráneo } \\
\text { del enemigo. }\end{array}$ & $\begin{array}{l}\text { Ingesta } \\
\text { del alimento. }\end{array}$ \\
\hline $\begin{array}{l}\text { 03. Teogonía e } \\
\text { historia de los } \\
\text { mexicanos. }\end{array}$ & $\begin{array}{l}\text { Los aztecas capturan } \\
\text { prisioneros. }\end{array}$ & $\begin{array}{l}\text { Los aztecas } \\
\text { ponen al } \\
\text { prisionero } \\
\text { en la piedra } \\
\text { de sacrificio. }\end{array}$ & $\begin{array}{l}\text { El sacerdote arranca } \\
\text { desde el pecho el } \\
\text { corazón palpitante. }\end{array}$ & $\begin{array}{l}\text { Sacerdote ofrece } \\
\text { el corazón a } \\
\text { Quetzacoatl y } \\
\text { Huitzilopochtli. }\end{array}$ \\
\hline $\begin{array}{l}\text { 04. Mito de la } \\
\text { creación en la } \\
\text { teogonía de } \\
\text { mexicanos. }\end{array}$ & $\begin{array}{l}\text { Los dioses } \\
\text { Quetzalcoatl y } \\
\text { Tezcatlipuca desean } \\
\text { hacer la tierra. }\end{array}$ & $\begin{array}{l}\text { Aprietan a } \\
\text { la diosa } \\
\text { Tlaltecutli y la } \\
\text { parten en dos: } \\
\text { cielo y tierra. }\end{array}$ & $\begin{array}{l}\text { Promesa de } \\
\text { compensar: } \\
\text { haciendo brotar } \\
\text { de Tlaltecutli } \\
\text { la naturaleza. }\end{array}$ & $\begin{array}{l}\text { La diosa } \\
\text { Tlaltecutli calma } \\
\text { su llanto comiendo } \\
\text { corazones } \\
\text { de hombres. }\end{array}$ \\
\hline $\begin{array}{l}\text { 05. Leyenda } \\
\text { de Licarayén. }\end{array}$ & $\begin{array}{l}\text { El cacique entrega a } \\
\text { su hija Licarayén. }\end{array}$ & $\begin{array}{l}\text { La joven } \\
\text { Licarayén } \\
\text { acepta } \\
\text { el sacrificio. }\end{array}$ & $\begin{array}{l}\text { El toqui } \\
\text { Quiltrapique } \\
\text { elegido para extraer } \\
\text { el corazón de } \\
\text { Licarayén. }\end{array}$ & $\begin{array}{l}\text { Quiltrapique extrae } \\
\text { el corazón de } \\
\text { Licarayén. }\end{array}$ \\
\hline
\end{tabular}




\subsection{La función del mito}

La función subyacente reveladora de la matriz que restituye la ley estructural del mito del ceremonial presente en el ritual, leído en la tríada de personajes del texto histórico de la Crónica de la Jornada de O magua y D orado, exhibe el propósito de nutrir simbólicamente al padre Lope de Aguirre, el generador del nuevo equilibrio entre los hombres marañones. El modelo representa al hijo Antón Llamoso desarrollando el ritual delante del padre Aguirre. Es decir, este hijo es quien ofrece una ofrenda (verbal y actitudinal) de expiación ante el padre con el propósito de conseguir el perdón de éste. De igual forma ocurre en la trama de la escena del sacrificio en "las tablas de las esteras mayas en que se ve a las víctimas extendidas sobre piedras de sacrificio, mientras el sacerdote levanta el brazo armado de un cuchillo" (Clissold, 1965: 22). Es decir, Antón Llamoso cumple la función de sacerdote, Martín Pérez, la de víctima y Lope de Aguirre, la del dios. Esto lo refiere el mismo Aguirre: "Y voz, hijo, Antón Llamoso, también dicen que queríades matar a vuestro padre" (Vásquez, [1561] 1986: 87); cuya relación explicita las funciones de padre, sacrificio e hijo.

Este ritual permite reconocer una actividad matriz que se exterioriza a través de recursos que están institucionalizados entre las comunidades naturales por donde Aguirre y sus marañones deben transitar. Una primera lectura hecha en el contexto cultural occidental revela horror y espanto, pues aquélla no es una actividad establecida; una segunda significación muestra una función simbólica de lo sagrado para la concepción de los naturales, ya que buscar la protección tras la inmolación de una víctima, como el proceder a la ingesta de la misma, o parte de la misma, no es algo cotidiano o exento de sentido. Encontramos la connotación, en la medida que reconocemos un propósito en ello, como el de expiar las culpas, borrar el mal o la ofensa ocasionada al dador de la gracia, del equilibrio de los mismos hombres marañones que lo acompañan; el bien llamado dador de la vida o la muerte: Lope de Aguirre.

Así también, el proceso de las dos secuencias binarias que esta trama analiza nos revela la relación funcional estrechamente entrelazada e insustituible de estos tres personajes que desarrollan roles específicos: Antón Llamoso es el hijo que debe recibir el perdón y en ello, la función de Martín Pérez es insustituible como la víctima y ofrenda ante los dichos y actos de Llamoso delante de Aguirre. Por su parte, este último es el padre quien, en consecuencia, da o quita el perdón, da o quita el equilibrio, da o quita la vida y finalmente, en un segundo sentido fuera de la lengua: permitirá la salvación. 


\subsection{Función del ritual}

La función del ceremonial del sacrificio es el de nutrir, aplacar la ira de un ser superior, otorgar fuerza bélica, aplacar la ira del genio maléfico, dar fuerza guerrera, en suma, alimentar, conquistar, subyugar para aplacar la fuerza del poder de un ser superior.

El esquema canónico planteado por Levi-Strauss en la fórmula [Fx (a): Fy (b) = Fx (b): Fa-l (y)] se cumple en la medida que los términos y las funciones de esta tríada justifican el ritual del perdón. En consecuencia diremos que: el esquema canónico de Levi-Strauss aplicado al texto de la Crónica de la Jornada de 0 magua y Dorado se cumple, en la medida que los términos y las funciones de esta tríada justifican el ritual de la salvación, supeditada al perdón. Esto acontece en la primera relación en que Aguirre acusa a Llamoso (a) lo que está en función (F) de la acusación (x), así como el que Llamoso niegue la acusación de Aguirre (b) está en función (F) de la negación (y); como es equivalente a que Llamoso succione la sangre y los sesos del enemigo (b), está en función (F) de la anunciación de la prueba por parte de llamoso (x), así como la prueba misma (y) está en función (F) de la acción de que Llamoso anuncie a Aguirre que acabará con el traidor (a) que, en un sentido subyacente y fuera de la lengua (- 1), justifica el perdón y conduce a la salvación de LLamoso. Agregamos que el ritual de salvación obedece a una explicación adicional en la fórmula complementaria y aclaratoria de la anécdota tras el mismo ritual.

De igual manera acontece en los textos: El camino deEI Dorado de Arturo Uslar-Pietri (1967), Lope de Aguirre, príncipe de la libertad. Miguel Otero Silva (1980) y La aventura equinoccial de Lope de Aguirre. Ramón Sender (1980); en la medida que la fórmula [Fx (a): Fy (b) = Fx (b): Fa-l (y)] no se altera, justificándose en los términos y las funciones de la tríada de personajes en el ritual del perdón y la consecuente salvación. Así, la primera relación en que Aguirre acusa a Llamoso de traidor o confabulador (a) está en función ( $\mathrm{F}$ ) del término de la acusación (x), así como el que Llamoso niegue la acusación de Aguirre, ya sea por sus antepasados o asegurando lealtad al mismo (b) está en función (F) de la negación (y); como es equivalente a que Llamoso anuncie la prueba a Aguirre de beber la sangre del traidor, beber la sangre y mascar los sesos de Pérez o, comer los sesos y el corazón del cobarde (b) está en función (F) de la anunciación (x), así como la prueba misma ejecutada por Llamoso, ya sea lamiendo la sangre y mascando los sesos del enemigo, succionando con sus labios los sesos del enemigo o, ensanchando con su daga la herida en el pecho de Pérez (y) está en función (F) de la acción de Llamoso de querer succionar la sangre y los sesos de su enemigo 
(a) que, en un sentido subyacente y fuera de la lengua (- 1) justifica la secuencia lineal que lleva al perdón y consecuentemente a la salvación de LLamoso, quien podrá mantenerse vivo y fuera de la ira de Aguirre. De esta manera, el curso de las acciones verbales y actitudinales de uno y del otro personaje dirigen este proceso a la deseada salvación, cuestión que está en el inconsciente de este hombre por la eventual pérdida de la libertad y lo que es más inmediato, la vida.

La secuencia del Popol Vuh, en la relación entre el Chilam o sacerdote Balam -la víctima- el dios Tohil comprendida en la trama, lleva a delimitar la acusación de captura comprendida en el rapto de hombres de la tribu de Vuc Amag, como el de regar la sangre en el camino (a) está en función (F) de la acusación de robo o rapto (x), así como el decir que el león mató a la víctima o se la comió (b) está en función (F) del término de negación (y); como es equivalente que Balam anuncie la prueba al dios Tohil como un ofrecimiento de sacrificio (b) está en función (F) de la anunciación de la prueba (x), así como la prueba de arrancar el corazón ante Tohil-dios (y) está en función (F) de la acción de que el pueblo acusa a Balam de robar o raptar a los hombres como el que Balam anuncie la prueba de sacrificio (a) que, en un sentido subyacente y fuera de la lengua (-1) justifica la acción y consecuentemente otorga la salvación pública del sacerdote Balam en nombre de su pueblo. De esta manera creemos, como lo plantea Lévi-Strauss, que el ritual de salvación de este mito obedece a una explicación de los naturales a querer obtener la salvación por medio de la función de la nutrición y el sustento de los dioses.

En cuanto a los Viajes y cautiverio entre caníbales de Hans Standen, la trama de la guerra entre Tupinambáes y Tupiniquins está señalada en el combate por la captura de prisioneros vivos o en el de dar muerte en combate al enemigo (a), que está en función (F) de la acusación o el de capturar a los prisioneros o bien darles la muerte (x), así como la alimentación del prisionero destinado a la ingesta (b) está en función (F) del término de negación comprendida en golpear el cráneo del enemigo (y); como es equivalente que obtener el beneficio del alimento (b) está en función (F) de la anunciación de la prueba de masacrar o golpear el cráneo (x), así como la ejecución de la prueba para obtener este alimento (y) está en función (F) de la acción de la captura de prisioneros vivos o el de dar muerte en combate a los enemigos (a) que, en un sentido subyacente y fuera de la lengua $(-1)$ justifica la acción de la prueba y consecuentemente otorga la salvación pública al combatiente de la tribu. Así como lo manifiesta Nunes, creemos que la función de pasar la prueba está en el propósito de nutrirse y de adquirir el poder y estatus del guerrero, o sea, honor y poder sobre los otros mortales. 
Si bien el texto seleccionado de la Teogonía ehistoria de los mexicanos da respuesta al mito de salvación, éste es una salvación comunitaria en que los aztecas capturan prisioneros para el sacrificio (a) que está en función (F) de la captura que en el texto de Omagua obedece a la acusación (x), así como los aztecas ponen al prisionero en la piedra de sacrificio (b) está en función (F) de la negación de la entrega que en el texto de Vásquez es la negación (y); como es equivalente a decir que el sacerdote ofrece el corazón a Quetzacoatl y Huitzilopochtli (b) está en función (F) de la anunciación de la prueba ante el dios y los hombres de la comunidad (x), así como la ejecución de la prueba está en función (F) de que el sacerdote arranque desde el pecho del ofrendado el corazón palpitante (a) que, en consecuencia y fuera del carácter lineal de la anécdota de la trama de alimentar, conquistar y subyugar para lograr la piedad del dios, lleva a la resolución del mito de la salvación colectiva.

En el contexto del mito de la creación en la Teogonía delos mexicanos, en que los dioses Quetzalcoatl y Tezcatlipuca desean hacer la tierra (a), está en función (F) del deseo, así como el que los dioses aprietan a la diosa Tlaltecutli y la parten en dos dando nacimiento al cielo y la tierra (b) está en función (F) de apretar y partir que obedece a la negación en oposición a la acusación en el texto de la Crónica de Vásquez; como es equivalente a decir que la diosa Tlaltecutli calme su llanto comiendo corazones de hombres está en función (F) de la promesa de compensación, así como la prueba al comer los corazones de hombres (y) está en función (F) de la promesa de compensarla haciendo brotar la naturaleza de la diosa Tlaltecutli (a), lo que fuera de la linealidad de la trama y de la lengua (-1) obedece a la salvación presente en el sustento del hombre, ya que la madre natura da los frutos tras el sacrificio de los corazones humanos.

En el contexto de las creencias en la cultura del pueblo mapuche, La leyenda de Licarayén refiere en la primera trama la entrega de Licarayén, la joven hija del cacique de la comarca (a) la que está en función (F) de la entrega, así como el hecho que la joven Licarayén acepte el sacrificio (b) está en función (F) de la aceptación de la entrega (y) que en el texto de Vásquez obedece a la acusación-negación; como es equivalente a decir que el corazón sea comido por un cóndor (b) está en función (F) de la anunciación a Quiltrapique de ser él el elegido para extraer el corazón (x), así como la prueba en la ejecución (y), obedece a la función (F) de la elección del joven Quiltrapique para convertirse en el sacerdote que extrae el corazón de la joven (a) que, fuera de la linealidad de la trama concebida en la lengua (-1), justifica el que la ingesta del corazón por un cóndor y llevar la hoja de canelo que cubrirá el cráter del mismo volcán Osorno aplacará la ira de un ser 
sobrenatural como el Pillán, habitante del centro del volcán, conduciendo a la salvación y al progreso de la comunidad.

\section{CONCLUSIONES}

En el eje de este estudio en donde hemos revisado una trama del texto de la Crónica de la Jornada de 0 magua y Dorado, la secuencia sintagmática ha sido leída en la relación de los términos: acusación y negación; anunciación y prueba, dando como consecuencia entre los textos precolombinos, un proceso similar del ceremonial en el triángulo vital sacerdote-víctima-dios; no obstante, las funciones justifican en cada discurso opciones similares aunque no idénticas en el proceso, sí en la consecución del don, el perdón, el alimento, aplacar la furia, entregar el poder, llevar el progreso a un lugar y a sus habitantes olvidados por un dios benefactor o poco propicio a las circunstancias.

Es considerable el número de escritores que en la literatura han trabajado el tema de Aguirre. Sin embargo, en cada caso éstos reproducen la anécdota reseñada por Vásquez con una particular visión; no obstante, aquí recreamos el ritual de salvación a partir de la encarnizada muerte individual, la que puede estar representada en las muertes colectivas cuando un dios mezquino o nada benefactor agosta a los habitantes o quita el alimento a una comunidad.

De manera que, al analizar la verdadera función significativa de la experiencia humana presente en esta tríada de conquistadores del texto de Vásquez y Pedrerías, concebida en la secuencia de la trama, contribuye a actualizar y dar sentido al ritual ya existente entre las comunidades precolombinas, quienes recreaban estos actos con un fin sagrado para obtener naturalmente la protección, el perdón, la libertad individual o grupal con la consecuente liberación o salvación también individual o grupal. Esto revela que Fx (a) = Fy (b), en donde la acción de dejar en libertad (a) está en función de perdonar (p), lo que es equivalente a decir que experimentar la libertad (b) obedece a la función de la salvación (s). Así y sólo así diremos que: $\mathrm{Fp}(\mathrm{a})=\mathrm{Fs}(\mathrm{b}) / \mathrm{P}=\mathrm{S}$. De esta manera, la significación de este primer sentido de la lengua que le da el primer sentido al ritual de salvación en donde Antón Llamoso promete y bebe la sangre y los sesos de Martín Pérez frente a Lope de Aguirre, se cuenta como un hecho natural a la hora de lograr el perdón de este último y con ello permitirle conservar la vida. Ahora bien, esta trama opera como vehículo significante para construir el sentido connotado, es decir, un segundo significado trabajado, primero, en la 
estructura sintagmática de la trama, luego en el reconocimiento de cada paradigma y, ahora, en la relación triádica del hijo que tras el sacrificio busca aplacar la ira del padre, asumiendo la prueba en el ritual. Por lo tanto, aplacada la ira del dios-padre todos pueden de ahí en adelante vivir "seguros y sin miedos" (Vásquez y de Almesto [1561] 1986: 88), o experimentando el perdón que se revela en la salvación $\mathrm{P}=\mathrm{S}$.

Además, queremos subrayar un fin bélico y político en los propósitos de Antón Llamoso, puesto que arremeter contra la víctima ya inmolada por la masa de hombres marañones guarda el propósito de mantenerse congraciado con su líder Lope de Aguirre; en donde esta acción es la antesala para mantenerse con vida ante un líder feroz que no perdona la traición, en suma, un dios-padre castigador y salvador a la vez.

En fin, lo que hemos desarrollado nos permitió confluir en el carácter sagrado y abierto de las culturas primitivas no cristianas que, por cierto, conectamos con el comportamiento entre los naturales de las comunidades del entorno histórico asumido por Antón Llamoso al naturalizarse como estaban aquellos Omaguas. En este sentido compartimos la visión de Mircea Eliade (1999), quien deja fuera el concepto cristiano del sacrificio que lleva a la resurrección y la salvación del alma, ya que, en éste, la idea del juicio final tiene un análogo tema "cerrado" y no como acontece en el simbolismo de los rituales precolombinos que se manifiestan de manera "abierta"; puesto que el hombre, en donde el mito es algo latente, vivió y vive en un mundo cíclico.

El peso conferido por el elemento ritual de la trama revisada en esta tríada de personajes: Antón Llamoso, Lope de Aguirre y víctima (Martín Pérez) nos permitió pasar del hecho manifestado por la lengua natural a aquél de la significación subyacente, el cual sólo es aprehensible en el contexto del mito revelador de los modelos ejemplares en los ritos y actividades humanas significativas: el hijo que busca alcanzar el perdón del padre mediatizado por el ritual del perdón conducente a la salvación.

\section{REFERENCIAS}

Bowra, C.M. 1996. La Grecia clásica. La herencia eterna. Vol. I. Barcelona: Folio. Clissold, Stephen. 1965. Perfil cultural de Latinoamérica. Barcelona: Editorial Labor S.A.

Eliade, M. 1999. Mito y realidad. Barcelona: Kairós.

Garibay, Ángel. 1973. Teogonía e historia de los mexicanos. México: Editorial Porrúa S.A. 
Gutiérrez, Manuel. 1988. M ito y ritual en América. Madrid: Alhambra.

Hozven, Roberto. 1979. El estructuralismo literario francés. Santiago: Ediciones del Departamento de Estudios Humanísticos Universidad de Chile.

Jung, Carl. 1995. El hombrey sus símbolos. Barcelona: Paidós.

Leal, Alejandra. 2008. "Ritual de Salvación en la Crónica dela Jornada de O magua y D orado". Ponencia presentada en el XV Congreso Internacional de la Sociedad Chilena de Estudios Literarios. Temuco, mayo.

Lévi-Strauss, Claude. 1976. "La estructura de los mitos". Antropología estructural. Buenos Aires: Editorial Universitaria, 186-210.

Mediz Bolio, Antonio (traductor). 1952. Chilam Balam de Chumayel. México: Ediciones de la Universidad Nacional Autónoma de México.

Nunes, Clicie. 1988. "Viajes y cautiverio entre los caníbales, de Hans Standen: Introducción a una historia de las figuraciones de la Colonia portuguesa en América”. Tesis de maestría. Concepción: Universidad de Concepción.

Otero Silva, Miguel. 1980. Lope de Aguirre, príncipe de la libertad. Barcelona: Seix Barral.

Recinos, Adrián (traductor). 1952. Popol Vuh. Antiguas historias del Quiché. México: Fondo de Cultura Económica.

Sender, Ramón. 1980. La aventura equinoccial de Lope de Aguirre. Madrid: Editorial Magisterio Español.

Uslar Pietri, Arturo. 1967. El camino de El Dorado. Buenos Aires: Losada.

Vásquez, F. y De Almesto, P. 1986. Jornada de Omagua y Dorado. Crónica de Lope de Aguirre 1561. Madrid: Ediciones Miraguano. 